\title{
PWE-111 IS THERE A GENDER SPECIFIC RESPONSE OF OESOPHAGEAL MUCOSA TO ACID REFLUX?
}

doi:10.1136/gut.2011.239301.374

S Menon, 1,* C Tselepis, ${ }^{2}$ M Anderson ${ }^{3}$ Department of Gastroenterology, Sandwell General Hospital, West Bromwich, UK; ${ }^{2}$ School of Cancer Sciences, University of Birmingham, Birmingham, UK; ${ }^{3}$ Department of Gastroenterology, City Hospital, Birmingham, UK

Introduction Oesophageal adenocarcinoma has an unexplained male predominance. We hypothesise that male and female oesophageal tissues display differential responses to acid reflux and progression of Barrett's metaplasia.

Aims To characterise the gene expression in male and female normal oesophagus and Barrett's metaplasia, to detect genderspecific differences.

Methods 12 biopsy samples of normal oesophagus and Barrett's with intestinal metaplasia were obtained ( 6 males, 6 females). Gene expression profiles were assessed by tissue microarray analysis to determine differences in upregulated gene expression. Real-time PCR was performed to assess differences in the upregulation of key genes (cdx-1, cdx-2, PCNA).

Results Using a Venn diagram filter to detect genes that were dysregulated in all three stratification pools (normal vs Barrett's in males, normal in males vs females, Barrett's in males vs females), 5 genes were identified: DAZ1, DAZ2, CCL4, RPS4Y1, USP9Y. The expression of DAZ1 is threefold higher in male Barrett's and is localised to the Y-chromosome.

PCR results suggest the upregulation of $c d x-2$ and PCNA in Barrett's metaplasia is greater in males.

Conclusion We provide evidence of gender-specific differences in the reflux-Barrett's pathway.

We have identified a novel set of biomarkers in male Barrett's specimens.

Further analysis of these genetic markers through immunohistochemistry and rt-PCR is planned.

Competing interests None.

Keywords Barrett's oesophagus, gender. 